\author{
Proceedings of the ASME 2012 Pressure Vessels \& Piping Division Conference \\ PVP2012 \\ July 15-19, 2012, Toronto, Ontario, CANADA
}

PVP2012- 78826

\title{
PU/SS EUTECTIC ASSESSMENT IN 9975 PACKAGINGS IN A STORAGE FACILITY DURING EXTENDED FIRE
}

\author{
Narendra K. Gupta \\ Savannah River National Laboratory \\ Aiken, SC 29808 \\ nick.gupta@srnl.doe.gov
}

\begin{abstract}
In a radioactive material (RAM) packaging, the formation of eutectic at the $\mathrm{Pu} / \mathrm{SS}$ (plutonium/stainless steel) interface is a serious concern and must be avoided to prevent of leakage of fissile material to the environment. The eutectic temperature for the $\mathrm{Pu} / \mathrm{SS}$ is rather low $\left(410^{\circ} \mathrm{C}\right)$ and could seriously impact the structural integrity of the containment vessel under accident conditions involving fire. The 9975 packaging is used for long term storage of $\mathrm{Pu}$ bearing materials in the DOE complex where the $\mathrm{Pu}$ comes in contact with the stainless steel containment vessel. Due to the serious consequences of the containment breach at the eutectic site, the $\mathrm{Pu} / \mathrm{SS}$ interface temperature is kept well below the eutectic formation temperature of $410^{\circ} \mathrm{C}$. This paper discusses the thermal models and the results for the extended fire conditions $\left(1500^{\circ} \mathrm{F}\right.$ for 86 minutes) that exist in a long term storage facility and concludes that the 9975 packaging $\mathrm{Pu} / \mathrm{SS}$ interface temperature is well below the eutectic temperature.
\end{abstract}

\section{INTRODUCTION}

The issue of eutectic formation for the PU/SS or PU/Fe has been extensively studied in the LANL, the ANL and the SRNL. ${ }^{[1-4]}$ It was stated that sufficient safety margin existed in the existing packagings. However, it was recommended that each storage condition be analyzed for unique fire scenarios to ensure that sufficient safety margin existed for each condition. The eutectic issue has also been addressed in DOE-STD-3013-2004. ${ }^{[5]}$ That standard concluded that plutonium can be stored in stainless steel containers up to $250^{\circ} \mathrm{C}$ for 10 years or more without significant eutectic formation.

The 9975 package is designed to meet the design requirements of 10 CFR Part 71 . The package was originally designed for transporting the radioactive materials (RAM) across the DOE complex and not for long term storage. As per 10 CFR Part 71.73, the minimum pool fire test requirements for the 9975 are $800^{\circ} \mathrm{C}$ for 30 minutes and subsequent cooldown under natural (no forced cooling) conditions with insolation. The fire conditions for the storage facility where 9975 is used for long term storage are $1500^{\circ} \mathrm{F}$ for 86 minutes (extended fire), with cool down under rather unknown or ill-defined conditions. An ill-defined condition analyzed in this paper is the smoldering of hot fiberboard (after 86 minutes fire) used as the impact limiter and the fire insulator in the 9975 packaging. An extended fire exposure coupled with potential smoldering of the fiberboard could raise the $\mathrm{Pu} / \mathrm{SS}$ interface temperature to $410^{\circ} \mathrm{C}$ or higher to form eutectic in the containment vessel.

The statement above assumes that during fire scenarios, a plutonium-iron (Pu-Fe) eutectic alloy will form and then fail a stainless steel container by melting or other mechanisms. The phase diagram in Figure 1 shows eutectic melting points of plutonium-iron alloys. Of chief concern is the eutectic melting point for $90 \%$ plutonium and $10 \%$ iron, at $410^{\circ} \mathrm{C}$. Plutonium with $1 \%$ gallium forms a eutectic with iron that melts at $400^{\circ} \mathrm{C}$. Pure plutonium melts at approximately $640^{\circ} \mathrm{C}$.

\section{Package}

The 9975 package is a very versatile Type B package which is certified to transport and store a wide spectrum of radioactive materials. The 9975 has double containment, namely, primary containment vessel (PCV) and secondary containment vessel (SCV) and a lead shield for added protection against radiation leakage. The packaged is designed to ship heat sources up to 19 watts. Figure 2 is a schematic of the 9975 package. The package is about 36-inch high and 18-inch in diameter. The package is certified to transport several content configurations including Food-Pack cans, and 3013 containers with LLNL, Rocky Flats, SRS convenience cans, etc. Contents for the package are placed

This work was prepared under Federal Contract DE-AC09-08SR22470. The United States Government retains, and by accepting the article for publication, the publisher acknowledges that the United States Government retains, a non-exclusive, paid-up, irrevocable worldwide license to publish or reproduce the published form of this work, or allow others to do so, for United States Government purposes. 
within the PCV, which is closed with a cone seal plug that has a set of double O-rings.

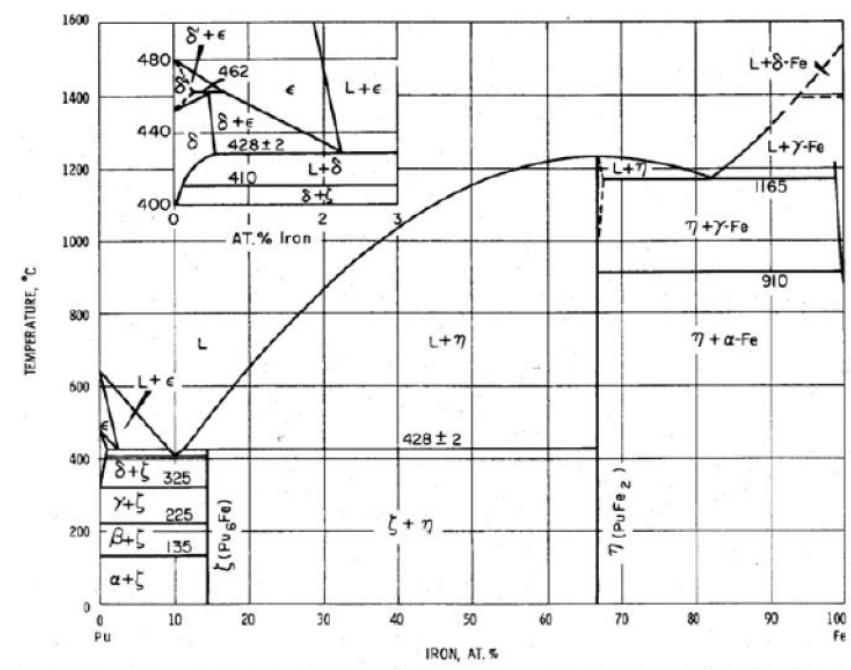

Figure 1 - Pu Phase Diagram

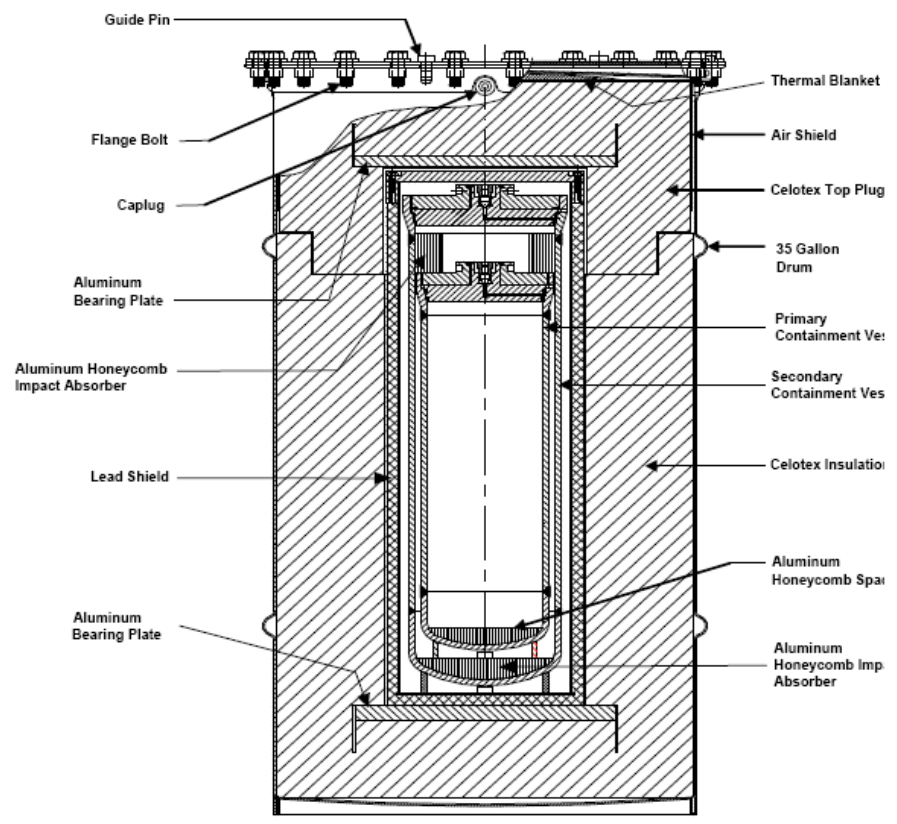

Figure 2 - 9975 Packaging

\section{Packages in Storage}

Figure 3 shows a typical array storage configuration of RAM packages in a facility. The arrangement is a Stacked-3 configuration where 3 groups of 4 packages are stored on top of each other. A view of this storage arrangement is important because it sets up the storage arrays for a potential collapse in an extended fire. If the storage arrays collapse, the packages will fall in a random fashion. A drop with the drum surface at nearly $1500^{\circ} \mathrm{F}$ could easily fracture the fiberboard protection boundary and expose the thermally degraded, carbon rich, hot fiberboard (char) to oxidizing atmosphere. This exposure could result in smoldering condition.

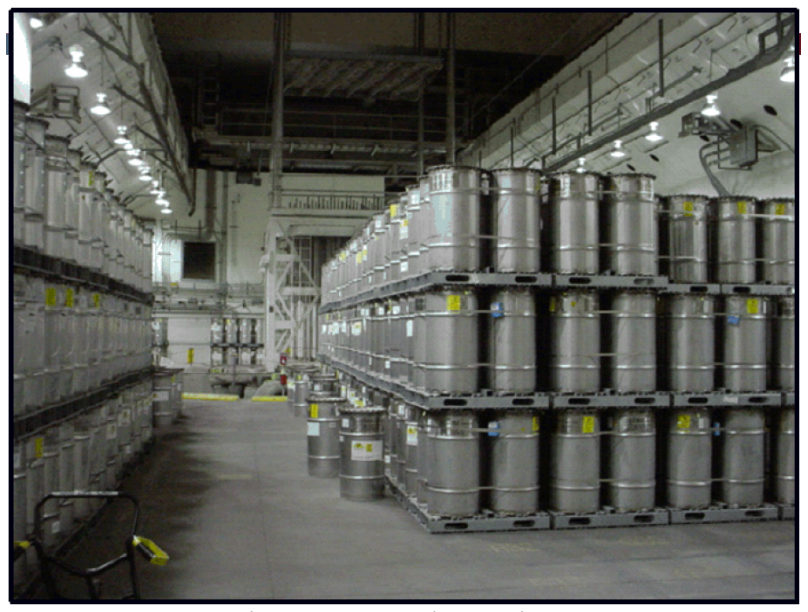

Figure 3 - Packages in Storage

Two drop scenarios are considered. They are:

1. Drum falls on its bottom resulting in a partial or a complete fracture of the bottom and then topples on to its side with the char at the bottom exposed to the air.

2. Drum falls on its side on a sharp object and rolls over. It is envisioned that the fall will puncture the drum skin and the rolling action peels off the drum skin, exposing the exposed char to the air.

\section{Package Functional Requirements}

Critical components of the 9975 package during fire conditions are its containment vessels (PCV and SCV), the seals and the lead shield. The containment vessel seals are Orings that must be maintained below certain temperature for the seals to remain leaktight. During fire, the impact limiter cane fiberboard $\left(\right.$ Celotex $^{\mathrm{TM}}$ ) provides protection from excessive heating of these components. Under these conditions, good fiberboard and its char provide the required protection. Table 1 gives the temperature limits for these components for their structural and thermal integrity.

Table 1: Component Temperature Limits

\begin{tabular}{||c|c|}
\hline Component & $\begin{array}{c}\text { Temperature } \\
\text { Limits }\left({ }^{\circ} \mathrm{F}\right)\end{array}$ \\
\hline O-Rings & 400 \\
\hline PCV \& SCV & 300 \\
\hline Lead Shield & 622 \\
\hline $\begin{array}{c}\text { PCV } \\
\text { (for eutectic protection) }\end{array}$ & $\begin{array}{c}770 \\
\left(410^{\circ} \mathrm{C}\right)\end{array}$ \\
\hline
\end{tabular}




\section{MATHEMATICAL MODEL}

The heat transfer governing equations for unsteady state system in axisymmetric cylindrical coordinates $(\mathrm{r}, \mathrm{z})$ are:

$$
k_{1} \frac{\partial^{2} T}{\partial r^{2}}+\frac{k_{1}}{r} \frac{\partial T}{\partial r}+k_{2} \frac{\partial^{2} T}{\partial z^{2}}+q^{\prime \prime \prime}=\rho C_{p} \frac{\partial T}{\partial t}
$$

Where $q^{\prime \prime \prime}(\mathrm{r}, \mathrm{z})$ is the volumetric heat generation by the fissile material per unit time, $\mathrm{T}$ is the temperature and $k_{l}$ and $k_{2}$ are the thermal conductivities of different materials in the radial (r) and axial (z) directions respectively. In general, $k_{l}$ and $k_{2}$ are functions of $\mathrm{r}, \mathrm{z}$, and T. $\rho$ is the density and $\mathrm{C}_{\mathrm{p}}$ is the specific heat of various materials. $\rho$ is constant and $C_{p}$ could vary with temperature for certain materials.

The boundary conditions are:

- Heat transfer coefficient $(h)$ at the drum outer surface,

- Emissivity $(\varepsilon)$ at the drum outer and inner surfaces and at other radiating surfaces inside the package, and

- Air temperature $\mathrm{T}_{\mathrm{a}}=1500^{\circ} \mathrm{F}$.

The partial differential equation (1) is non-linear and is solved by numerical methods using MSC PATRAN Thermal solver. ${ }^{[6]}$

\section{THERMAL MODELS}

Thermal analyses are divided into two main models. Part 1, called the Fire Model, covers 86-minutes of fire and Part 2, called the Smoldering Model, covers the smoldering analysis following the fire. Part 1 was analyzed in a separate analysis $^{[7]}$ and forms the initial condition for the Part 2. Part 1 is not described here.

In Part 1, the package was analyzed in an engulfing fire of $1500^{\circ} \mathrm{F}$ and 86 minutes long. The char and un-charred fiberboard thicknesses after the fire are shown in Table 2.

Table 2 - Char Depth

\begin{tabular}{|c|c|c|c|c|c|}
\hline \multirow[b]{2}{*}{ Location } & \multicolumn{4}{|c|}{ Time (minutes) } & \multirow{2}{*}{$\begin{array}{c}\text { Un-charred } \\
\text { Fiberboard } \\
\text { (in.) }\end{array}$} \\
\hline & 0 & 30 & 60 & $\begin{array}{c}86+ \\
\text { Cooldown }\end{array}$ & \\
\hline Side & 0 & 0.90 & 1.95 & 2.95 & 1.88 \\
\hline Top & 0 & 1.05 & 1.85 & 2.00 & 1.70 \\
\hline Bottom & 0 & 0.934 & 1.90 & 2.80 & 1.00 \\
\hline
\end{tabular}

An estimate of the un-charred fiberboard thickness will be useful in formulating the smoldering models. A char is not a well-defined material, but typically it is considerably richer in carbon content than the original material. There are three distinct temperatures that are observed during thermogravimetric analysis of the fiberboard samples. ${ }^{[8]}$ These are: the start of thermal decomposition at $410^{\circ} \mathrm{F}$, the maximum decomposition at $770^{\circ} \mathrm{F}$, and the final decomposition of remaining organic materials at temperature $932^{\circ} \mathrm{F}$ and above. Based on these observations, fiberboard at or above $770^{\circ} \mathrm{F}$ is considered char. This is the carbon rich residue that will be compressed in a drop situation and will be prone to smolder if exposed to the air conditions.

\section{Initial Conditions for Part 2}

Figure 4 shows the temperature profiles after 86 minutes of fire. Fiberboard at or above $770^{\circ} \mathrm{F}$ is considered char.

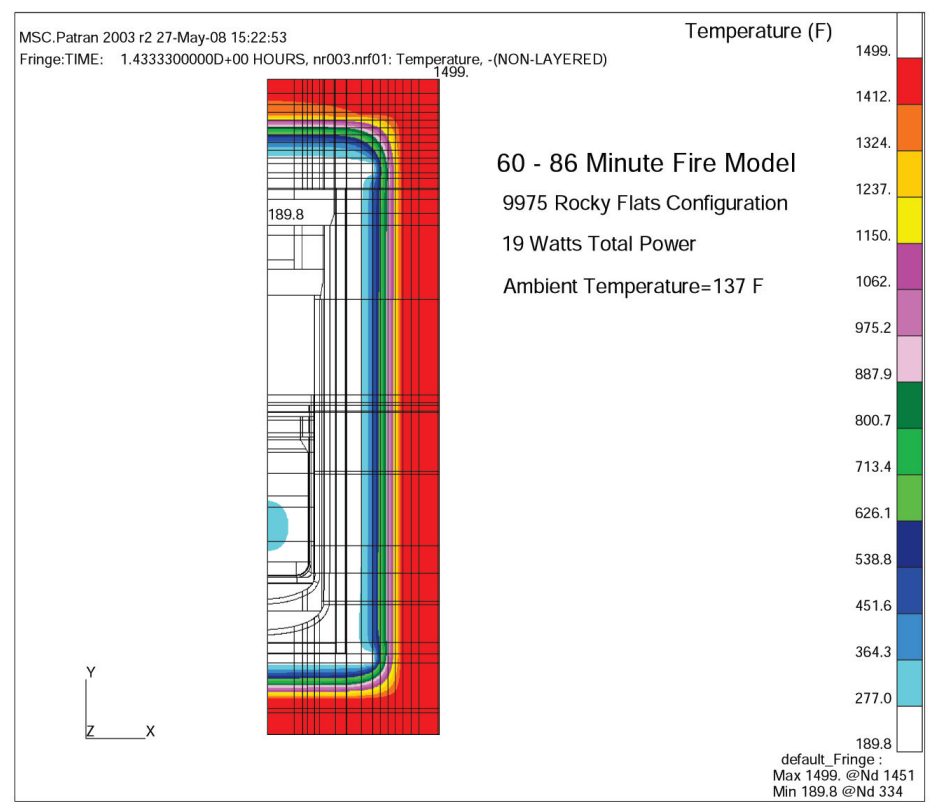

Figure 4 - Temperature profile after 86 minutes of KAMS fire

\section{Simplifying Assumptions}

Due to the difficulty in defining the precise nature of the array collapse and the subsequent package drop and boundary failures, simplifying assumptions are made to enable modeling and simulation of the potential smoldering phenomenon. Following assumptions are made to simulate the two drop scenarios mentioned above.

1. In the bottom drop, the entire bottom of the package falls off exposing the bottom fiberboard to the potential smoldering condition

2. In the side drop, the package drops flat on a 12" sharp object and the entire 12" wide drum skin is peeled off in the ensuing roll.

3. About $75 \%$ of the original fiberboard thickness is compressed in the drop scenario.

The simplifying assumptions enable to model the two drops by axisymmetric models. Model 1 is the bottom drop and subsequent topple to expose the char at the bottom of the package. Model 2 is flat drop on the side and subsequent roll. 


\section{Smoldering of Fiberboard}

Smoldering is a slow, low-temperature, flameless form of combustion where the carbon rich char will keep burning smokeless and the hot temperature front will keep moving in the cooler char as long as there is enough supply of oxygen. (It is like a cigarette which will burn itself completely if the burning front can get the oxygen). For the 9975 package, the drum skin will normally prevent the exposed char from getting a continuous supply of the fresh air for prolonged smoldering unless a significant drum surface is torn apart. Therefore, it is envisioned that a small fracture in the drum skin would result in smoldering for a short time (few minutes) until a layer of char ash is formed that essentially blocks the supply of air to the smoldering front and extinguishes it. It is hard to imagine that a prolonged smoldering is feasible unless a large char surface is exposed and a supply of air is available. Therefore, for analysis purposes, it is assumed that the entire drum bottom is separated from the drum when the drum falls on its bottom thus exposing the char to the air. In the side drop a 12 inch fracture is assumed to peal off all around that exposes the char to the fresh air.

The smoldering temperature varies from $625 \mathrm{~K}$ to $920 \mathrm{~K}$ $\left(666^{\circ} \mathrm{F}\right.$ to $\left.1197^{\circ} \mathrm{F}\right)$ for the wood materials. ${ }^{[9]}$ It is assumed that the smoldering temperature is $1200^{\circ} \mathrm{F}$. Since there is no forced flow to remove the ash at the smoldering front, the smoldering will cease after a short time. So how long will the smoldering last?

The duration of smoldering will vary with the smoldering front velocity which in turn depends upon the component geometry, the amount of char exposed, and the supply of air. Smoldering front velocities of $0.09 \mathrm{~mm} / \mathrm{min}$ to $0.9 \mathrm{~mm} / \mathrm{min}$ depending on the oven temperature, air velocity, and types of woods have been reported in the literature. $^{[9]}$ In general, a small smoldering front (small fracture in the drum skin) will result in extinguishing of the front rather quickly due to ash build-up and limited supply of air while a large smoldering front (smoldering models assumed here) will promote higher front velocity and faster consumption of the char. Therefore, a front velocity range of $0.5 \mathrm{~mm} / \mathrm{min}$ (average) to $0.9 \mathrm{~mm} / \mathrm{min}$ is considered reasonable for the large char area assumed in the models here. Such front velocities are equal to $1.2 \mathrm{inch} / \mathrm{hr}$ to 2.2 $\mathrm{inch} / \mathrm{hr}$. The char thicknesses of about $1.1 \mathrm{in}$. and $0.91 \mathrm{in}$. are estimated in the bottom and side drops. Therefore, it is estimated that the smoldering will continue for about one hour before it dies down either due to exhaustion of the char or lack of oxygen to the smoldering front.

Model 1 - Figure 5 shows the axisymmetric view of the smoldering model following the bottom drop.

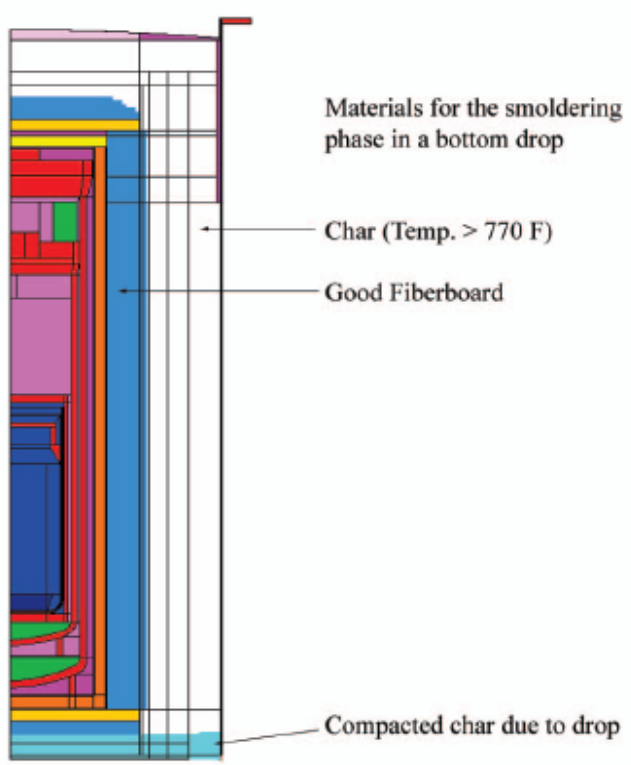

Figure 5 - Smoldering Fire Model for the Bottom Drop

Model 2 - Figure 6 shows the axisymmetric view of the smoldering model following the side drop.

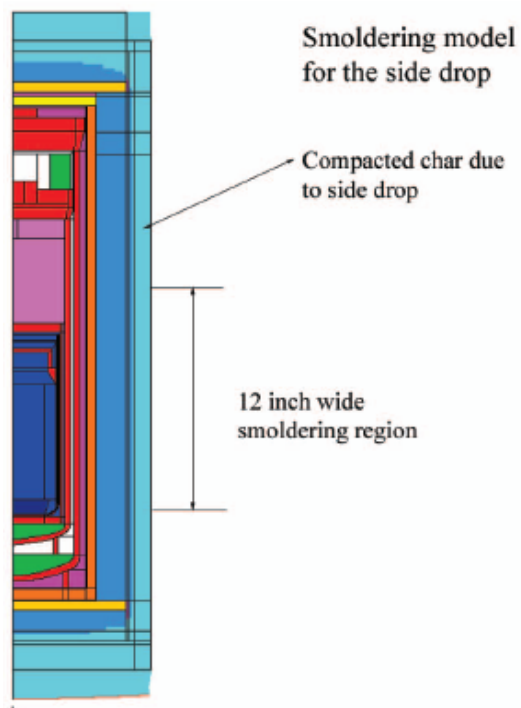

Figure 6 - Smoldering Fire Model for the Side Drop

\section{Postfire Phase Model}

After the smoldering phase is over, the package cools down to the room temperature. This is called the postfire phase. For the postfier phase, we are faced with the situation to estimate the amount of char/ash left in the package cavity and its thermal properties. Two extreme cases are examined: 1) char is assigned properties as determined in the furnace tests and. 2) the char is estimated as mixture of gases, and assigned air properties without radiation cooling. It was found that the second case gave higher component temperatures. 


\section{RESULTS}

Figure 7 gives the temperature profiles for the bottom drop after one hour of smoldering.

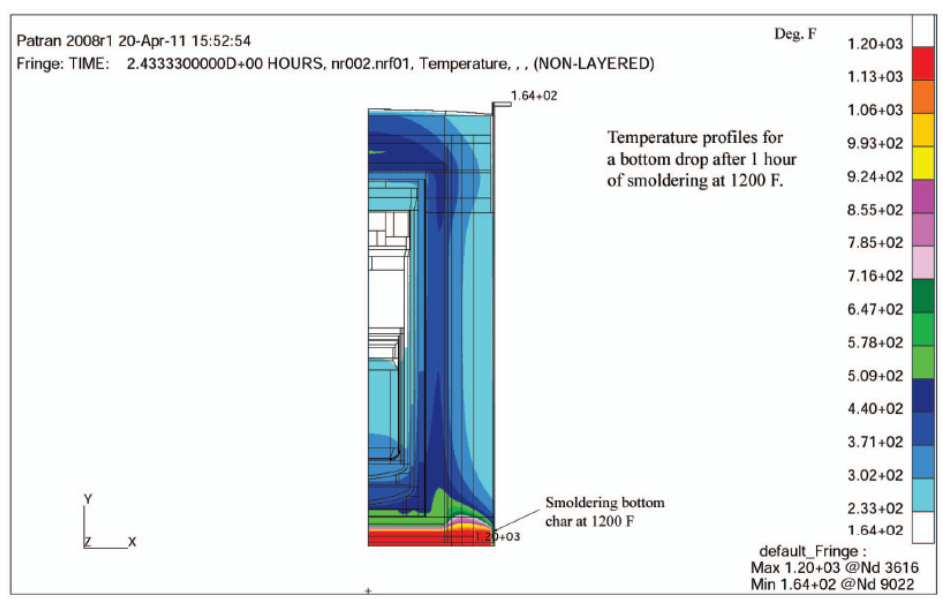

Figure 7 - Temperature Profiles after Smoldering in a Bottom Drop

Figure 8 gives the temperature profiles for the side drop after one hour of smoldering.

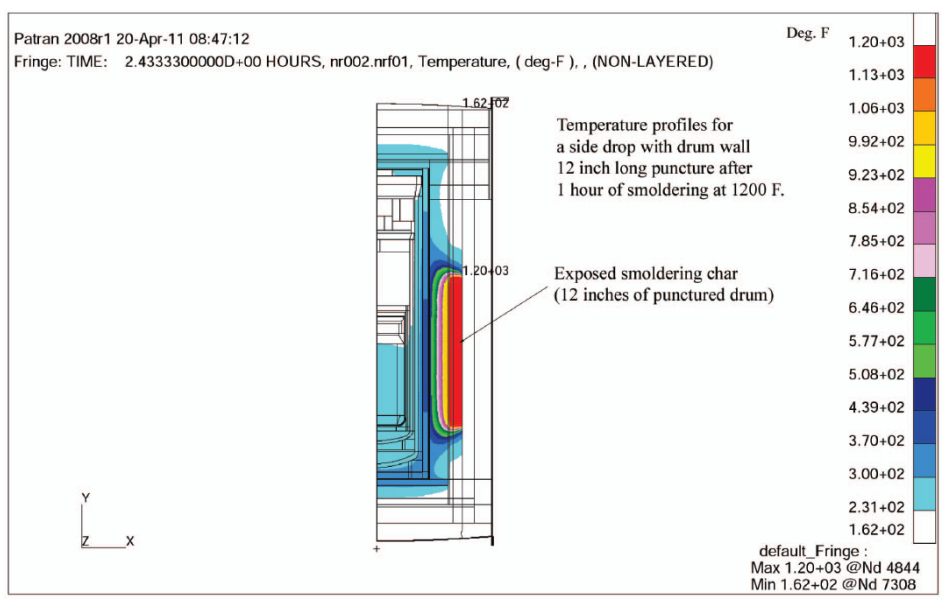

Figure 8 - Temperature Profiles after Smoldering in a Side Drop

Figures 9 and 10 show the temperature profiles for the 3013 container with the $\mathrm{Pu}$ button in place. The maximum temperature at the $\mathrm{Pu} / \mathrm{SS}$ interface is well below the eutectic formation temperature of $770^{\circ} \mathrm{F}\left(410^{\circ} \mathrm{C}\right)$.

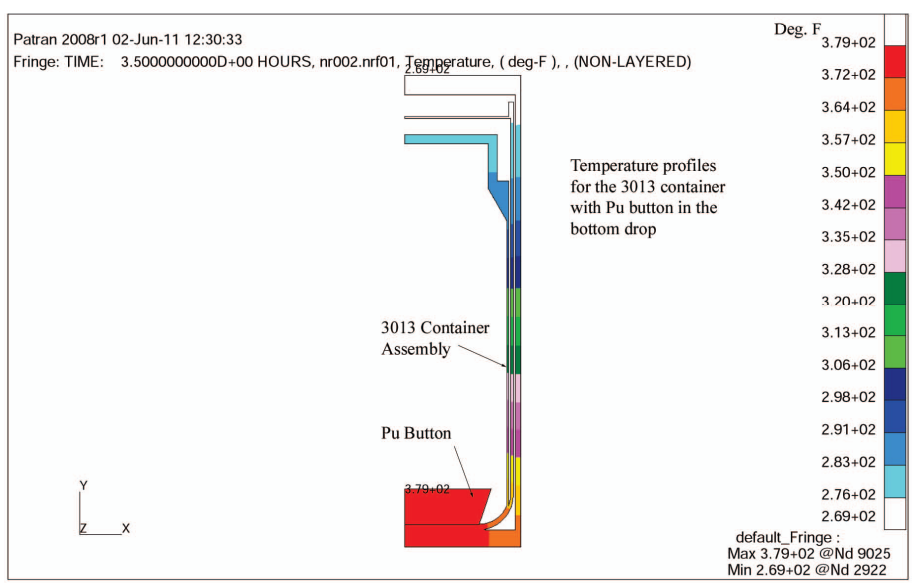

Figure 9: Maximum 3013 Container Temperatures in a Bottom Drop

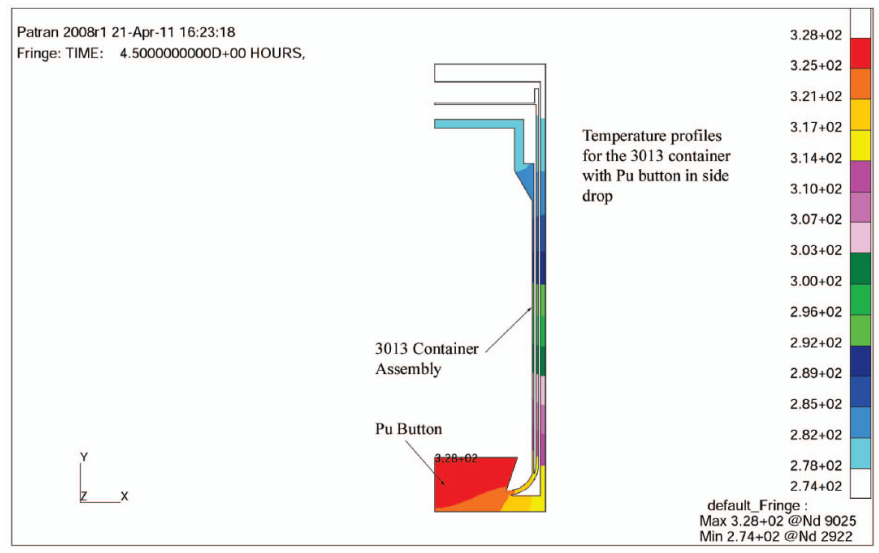

Figure 10: Maximum 3013 Container Temperatures in a Side Drop

Table 3 summarizes the maximum temperatures for the contents and the PCV/SCV 86-minute fire, smoldering, and the postfire cooling. The maximum temperatures reach during the cooldown phase. The maximum temperatures occur at about 4 hours into the fire.

Table 3: Contents and PCV/SCV Temperatures Summary

\begin{tabular}{||c|c|c|c|c|c|c||}
\hline \multirow{2}{*}{ Location } & \multicolumn{2}{|c|}{$\begin{array}{c}\text { 86-minutes } \\
\text { Fire }\left({ }^{\circ} \mathrm{F}\right)\end{array}$} & \multicolumn{2}{c|}{$\begin{array}{c}\text { 1-Hour } \\
\text { Smoldering }\left({ }^{\circ} \mathrm{F}\right)\end{array}$} & \multicolumn{2}{c|}{$\begin{array}{c}\text { Postfire } \\
\text { Phase }\left({ }^{\circ} \mathrm{F}\right)\end{array}$} \\
\cline { 2 - 7 } & Contents & PCV & Contents & PCV & Contents & PCV \\
\hline Bottom & 249 & 244 & 336 & 345 & 379 & 375 \\
\hline Side & 249 & 244 & 284 & 240 & 328 & 322 \\
\hline
\end{tabular}




\section{DISCUSSION}

The above described fire and smoldering models are deemed appropriately conservative because of the following factors:

1. The fire models described in Part 1 assume an engulfing fire. It is highly unlikely that the package will see the fire all around in the storage conditions. Since the assumed fire is an engulfing fire, the analyses are applicable for all locations in the storage area.

2. The assumption of thermal radiation in the air space created due to the removal of the decomposed fiberboard is conservative because of the much higher thermal diffusivity of air than the denser char.

3. Char formation of certain organic compounds occurs at approximately $500^{\circ} \mathrm{C}\left(932^{\circ} \mathrm{F}\right)$, well above the $770^{\circ} \mathrm{F}$ used in the models. Using a lower char temperature, more fiberboard material is removed than would occur in a real fire.

4. Exposing the entire char at the fracture site all around the drum surface in the smoldering phase is very conservative because the drum surface fracture will result in smoldering in a very small volume of the char.

5. The smoldering temperature is assumed at the upper end of the smoldering temperature range for the wood materials. In addition, the smoldering 1 inch char layer is set to $1200^{\circ} \mathrm{F}$ instantly rather than in 1 hour.

\section{CONCLUSIONS}

1. The maximum temperature of the PCV and SCV Orings is $292^{\circ} \mathrm{F}$ and is below their design limits. The $\mathrm{O}-$ rings are away from the smoldering char sites and are protected by the air shield at the top of the package.

2. The analyses show that the maximum temperature of the $\mathrm{Pu}$ metal and the stainless steel interface is $379^{\circ} \mathrm{F}$ and is well below the $410^{\circ} \mathrm{C}\left(770^{\circ} \mathrm{F}\right)$ eutectic formation limit. Since the heat load is concentrated in one $\mathrm{Pu}$ button and since there is considerable safety margin as regards to the eutectic formation potential, the analyses presented here are applicable to the $\mathrm{Pu}-$ metal contents in non-3013 containers also. Therefore, in general, there is no potential of forming eutectic in the 9975 payloads.

3. The analyses show that the maximum lead shield temperature is $515^{\circ} \mathrm{F}$ and is well below the melting temperature of $622^{\circ} \mathrm{F}$. The extreme conservatism in the bottom drop smoldering model gives confidence that $515^{\circ} \mathrm{F}$ is a bounding temperature and the integrity of the lead shield is not compromised.

\section{DISCLAIMER}

This document was prepared as an account of work sponsored by an agency of the United States Government. Neither the United States Government nor the Savannah River Nuclear Solutions (SRNS), LLC nor any of their employees, makes any warranty, express or implied, or assumes any legal liability or responsibility for the accuracy, completeness, or usefulness of any information, apparatus, product, or process disclosed, or represents that its use would not infringe privately owned rights. References herein to any specific commercial product, process, or otherwise, does not necessarily constitute or imply its endorsement, recommendation, or favoring by the United States Government or the SRNS. The views and opinions of authors expressed herein do not necessarily state or reflect those of United States Government or the SRNS, and shall not be used for advertising or product endorsement purposes.

\section{REFERENCES}

1. ORPS Report: EM-RL--PHMC-PFP-2005-0032 Potential eutectic failure mechanism for stainless steel 3013 cans containing plutonium metal not analyzed in the Safety Basis (USQ).

2. ORPS Report: EM-SR--WSRC-KAREA-2005-0002 PISA Declaration in K Area Complex. ORPS Report: NA-LASO-LANL-NUCSAFGRDS- 2006-0001 -Eutectic Reaction between Plutonium and Iron May Affect Plutonium Storage Requirements.

3. ORPS Report: NA--LASO-LANL-TA55-2006-0003 PISA: Eutectic Reaction between Plutonium and Iron May Affect Authorization Basis Requirements.6.

4. Tsai, H., Liu, Y. Y., Gupta, N. K., and Smith, A. C., Potential Eutectic Failure Mechanism for Stainless Steel 3013 Cans. RAMPAC web page, 2006.

5. DOE-STD-3013-2004, DOE Standard, Stabilizing, Packaging, and Storage of Plutonium-Bearing Materials, U.S. Department of Energy, Washington, DC, 2004.

6. MSC PThermal Finite Element Software, version 2003r2, Santa Ana, CA, (2008).

7. Gupta, N. K., Thermal Analysis of a 9975 Package in a Facility Fire Accident, Proceedings of the 2011 ASME Pressure Vessel and Piping Division Conference, Baltimore, MD, PVP2011-57005, 2011.

8. Varbel, J. L., White Paper: Demonstration of Equivalency of Cane and Softwood Based Celotex for 9975 Packaging, WSRC-TR-2007-00453, Savannah River Site, Aiken, SC, 2007.

9. Fernando de Souza Costa and David Sandberg, Mathematical Modeling of a Smoldering Log, Combustion and Flame, 139, 227-238, 2004. 